\title{
The epidemiology of stroke in a developing country (Pakistan)
}

\begin{abstract}
Ischaemic stroke is a major cause of neurological morbidity and mortality. The objective of this review article is to summarise facts pertaining to acute ischaemic stroke and its various aspects in a developing country like Pakistan, where resources are limited and the healthcare system is underdeveloped. No large-scale epidemiological studies are available to determine the true incidence of stroke in Pakistan. We conducted a study to determine the prevalence of several important stroke risk factors among Pakistani stroke patients, and to determine whether these risk factors differ among urban versus rural populations. We also used existing data from literature to compare overall stroke incidence in Pakistan to that in developed countries. We found that, unlike in most countries, where hypertension is the most important stroke risk factor, pregnancy/prolonged contraceptive use is the most important risk factor in our Pakistani sample. This risk factor is more prevalent in urban than in rural populations. With the exception of Germany, developed countries have lower stroke incidences than Pakistan. We highlight areas for future research.
\end{abstract}

Volume 8 Issue I - 2018

\author{
M Ishaq Khan,' Junaid I Khan, ${ }^{2}$ Sheikh I \\ Ahmed, ${ }^{3}$ Umer ul Haq ${ }^{4}$ \\ 'Walden University, USA \\ ${ }^{2}$ George Mason University, USA \\ ${ }^{3}$ Yusra Medical College, DHA Islamabad, Pakistan \\ ${ }^{4}$ Department of Neurology, AMC Rawalpindi, Pakistan
}

Correspondence: $M$ Ishaq Khan, Walden University I S Washington Ave \#9, Minneapolis, MN 554 I, USA, Tel + I-202873-3307,Tel + I-703-962-123 Email junaydkhan@gmail.com

Received: November 25, 2017 | Published: January 23, 2018

Keywords: Stroke, Pakistan, Developing Countries, Epidemiology, Risk Factors

Abbreviations: AF, Atrial Fibrillation; CT, Computed Tomogram; CVA, Cerebrovascular Accident; MRI, Magnetic Resonance Imaging; SES, Socioeconomic Status; TIA, Transient Ischemic Attack

\section{Introduction}

Epidemiologic studies on stroke help us to understand the natural history of the disease and to identify risks and prognostic factors that can lead to better knowledge of the markers for disease mechanisms. ${ }^{1}$ Epidemiological and observational data can inform scientists of possible unique areas for more focused research. Both could help identify the individuals, groups, or geographic areas that are at increased risk of disease or poorer prognosis. Study of predisposing factors for stroke can lead to a better understanding of the underlying causes. In addition, knowing which individuals, communities, or regions are at risk of stroke could help physicians and public health policymakers to build up more efficient, purposeful programs to diminish the risk of stroke-related outcomes such as morbidity and mortality. ${ }^{2}$

Stroke is a debilitating illness rendering thousands disabled and leading a significant proportion of people to death worldwide. Its incidence in Asia, according to a rough estimate, has been increasing recently. Among Asian countries, Pakistan shares a significant burden of this devastating disease, which contributes towards expenditure of resources in terms of finances, community manpower, health services, and the economy as a whole. ${ }^{3}$ According to recent research findings, traditional and well-known risk factors of stroke, like diabetes and hypertension, have also been recognised to be increasing in Asian countries. The burden of stroke is following a similar trend. According to recently published literature, currently Pakistan has an enormous proportion of its population suffering either from diabetes or hypertension or both. Unfortunately, a majority of people are unaware of their comorbid conditions. This primarily is due to a lack of awareness for routine medical check-up, availability of screening services for endemic diseases locally, and ignorance on the part of the community regarding personal healthcare. Even those who have been timely diagnosed mostly do not follow the standard practice of a regular follow-up and/or compliance with medications. ${ }^{4}$ At the same time, poor updated knowledge of local physicians not associated with tertiary care setups contributes towards the use of obsolete and relatively less effective medical healthcare delivery.

The current incidence and prevalence of stroke in Pakistan is not exactly known. Several reported case series in literature highlighting significant differences in terms of stroke epidemiology and risk factors for stroke subtypes. However, actual data are still not available. Regarding Pakistan, the current published literature is insufficient, and original research articles are not more than a few in number. ${ }^{5}$ Pakistan has the world's highest rate of stroke per capita, so it would be highly beneficial to collect and interpret local epidemiological data. A timely and appropriate management of stroke can help in minimizing morbidity/mortality of stroke and the tremendous health care cost. ${ }^{6}$ The intent of this article is to clarify the important risk factors of stroke (cerebrovascular accident [CVA]) in Pakistan. Through this study, we primarily aim to present the current epidemiological stroke risk factor data in Pakistan, as well as to juxtapose stroke incidence in Pakistan with that of the developed world. We also intend to highlight areas for future development and improvement in management.?

In China, epidemiological data about stroke at national level are not known. ${ }^{8}$ The stroke prevalence rate in 2013 was $1,596 / 100,000$ individuals. Radiological investigations such as CT scan and MRI showed the prevalence of stroke at $90 \%$, with incidence at $83 \%{ }^{9}$ In men aged $\geq 45$ years, the age-specific stroke prevalence was significantly greater than in women $(\mathrm{p}<0.001)$. In China, the most important preventable risk factors are high blood pressure, alcohol abuse, and smoking. As of today, for stroke, the most important preventable risk factor is hypertension. As of 2013, the stroke prevalence estimates were statistically greater than those documented in China 30 years earlier, in particular amongst rural inhabitants. ${ }^{10}$

In Pakistan, the indigenous epidemiological data are inadequate. The current incidence and prevalence of stroke in Pakistan is not exactly known. Several reported case series in literature highlighting significant differences in terms of stroke epidemiology, risk factors, 
and stroke subtypes have been published. ${ }^{11}$ For a better understanding of the cause and effect risk factors, it is imperative to work on the information related to the indigenous population. Ignoring the burden of stroke may have health and economic costs.

The purpose of this study was to expand on epidemiological stroke data for Pakistan by answering the following research questions:

i. What are the percentages of incidence of risk factors in Pakistani stroke patients?

ii. Are there differences in the percentage patients with risk factors between urban and rural stroke patients?

iii. Is there a difference between Pakistani incidence of stroke and developed nations?

We used a combination of primary and historical data drawn from literature to answer the research questions. After presenting a literature review on stroke management in Pakistan, we present the methodology of the study, followed by our results and conclusions.

\section{Literature review}

The objective of this review is to highlight the health care and economic limitations of management of stroke in Pakistan, where there is still research work to be done, and where there are scarce resources for handling the real health problem of stroke. We reviewed and compared current research from other countries to the epidemiological data of Pakistan. ${ }^{12}$ This is important to clarify the gap in knowledge and limitations faced in the management of stroke.

\section{Definitions and diagnosis}

Stroke, or CVA, is a well-known condition causing a substantial communal burden including disability, neurological morbidity, and mortality .The diagnosis of stroke depends upon clinical observations. According to the World Health Organization, stroke is defined by "rapidly developing clinical signs of focal disorder of cerebral function, with symptoms enduring 24 hours or over and could lead to death, with no obvious cause other than of vascular origin". ${ }^{13}$ Standards for classification of stroke subtypes have not been fully understood and may fluctuate from one study to another. As a consequence, epidemiological studies may underestimate the total burden of cerebrovascular disease.

Distinction between ischemic and haemorrhagic infarction can only be obtained by computed tomogram (CT) immediately after the incidence of stroke or at autopsy. Clinical and diagnostic test criteria make subarachnoid haemorrhage a distinct epidemiological entity because, in most cases, these patients are admitted to hospital or die before medical attention can be sought. Therefore, it is imperative to make out the subarachnoid haemorrhage as a distinctive epidemiological entity before these cases become more serious and seek medical treatment.

Transient ischemic attack (TIA), or "mini-stroke", is a subtype of stroke with recent difficulty in definition. Originally, TIA was defined based on the duration of the event. An expert group recently suggested a formal change in the definition of TIA to a "transient episode of neurological dysfunction caused by focal brain, spinal cord, or retinal ischemia, without acute infarction," thereby abolishing the time-based component documented in the classical definition. ${ }^{14}$ The conclusion to use a tissue-based (not an arbitrary time based) definition of TIA was primarily driven by modern imaging data, which discovered that as many as $50 \%$ of patients with momentary deficits lasting $<24$ hours have evidence of brain ischemia on initial magnetic resonance imaging (MRI), and 50\% of those with initial abnormalities on MRI show substantiation of fixed infarction on following images. ${ }^{15}$

\section{Prevalence and incidence}

The global impact of stroke seems to be even more pronounced than it is in the United States, but estimates of the disease burden in developing countries vary widely. ${ }^{16}$ In most industrialized populations, stroke is the third most important cause of death, hospital admission, and long-term disability. Our study took place in the developing country of Pakistan. In Pakistan, there was a crude age-and sexadjusted stroke incidence of 95 per 100,000 persons per year for the years 2000 to 2016, with the highest incidence being 584,000 of 650,000 , noted among individuals aged 75 to $85 .{ }^{17}$ Other populationbased TIA incidence rates average25per 100,000 persons per year from 2014-2016. ${ }^{18}$ The risk of possible vascular events within 3 months is elevated after TIA, as after stroke, and this risk is uppermost within the first week after TIA. According to recent studies, there is $10 \%-20 \%$ risk of stroke for a 90 -day period after TIA. Based on this finding, prediction scores have been developed and validated to facilitate better decision making in the evaluation of imminent risk of stroke after TIA. ${ }^{19}$ Similar scores could potentially be engaged to identify TIA patients who may need admission, but have not yet been tested clinically. In ongoing epidemiological studies, cerebral ischemia noticed on brain imaging among asymptomatic persons aged 50 to 64 years is $12 \%$, and for those individuals aged $\geq 70$ years, $43 \%$ .$^{20}$

\section{Risk factors}

In order to reduce the burden of stroke, prevention still remains the best therapeutic at the global level. There are several published studies on stroke risk factors in Pakistan. ${ }^{21-49}$ One follow-up study helped in the identification of two groups of risk factors: Preventable and non preventable risk factors. The latter is associated with high stroke risk ${ }^{50}$ whereas the former is associated with relatively lower risk of stroke. Preventable risk factors are open to intervention for lower stroke risk; these include diabetes mellitus, cardiovascular causes such as high blood pressure, raised cholesterol, smoking, valvar heart diseases, obesity/hyperlipidaemia, sedentary habits, diet high in fats and carbohydrates, neuropsychiatric disorders, and postoperative conditions.

Preventable health risk factors: High blood pressure (hypertension) is the most well-known adaptable risk factor for ischemic stroke, and it affects over 75 million adult's $\geq 20$ years of age in the United States. ${ }^{51}$ Because of its high prevalence, the population-based risk of hypertension for stroke is approximately $40 \%{ }^{52}$ while in some studies the population-based risk has been even higher, at 50\%-60\% ${ }^{53}$ The prevalence of hypertension is directly related to lifestyle and the degree of mental stress and strain. In the current study, most of the patients with cerebrovascular stroke had high blood pressure (patients with blood pressure brain stroke, less than systolic). ${ }^{54}$

Cardiac arrhythmia, or chronic atrial fibrillation (AF), is a strong stroke risk factor and is likely to involve over 2.6 million individuals in the United States, according to 2010 data..$^{55}$ The prevalence of AF in individuals $30-65$ years of age is about $6 \%$. Since the prevalence of $\mathrm{AF}$ rises with age, the causative risk of stroke due to $\mathrm{AF}$ is greatest in older age groups.$^{56}$ So, for example, AF may account for as much as $20 \%-25 \%$ of strokes in individuals aged 30 to 90 years. The risk is about 20 times greater in those with valvar heart diseases (in particular rheumatic) and nearly 6 times greater in those with non-valvar heart diseases. Clinical trial and epidemiological data have been used to derive various stroke risk stratification schemes that can be used in 
clinical practice for AF patients..$^{57}$ Of note, outpatient continuous arrhythmia monitoring is increasingly showing that AF may actually be responsible for a higher percentage of unexplained strokes than was previously known. ${ }^{57}$

Individuals with coronary artery disease have twofold the risk of stroke compared with patients without coronary artery disease..$^{58}$ Patients with coronary artery disease with left ventricular hypertrophy have nearly three times the risk of stroke, while those with coronary artery disease and congestive heart failure have about a fourfold higher risk of developing stroke. ${ }^{59}$ In patients with old myocardial infarction of about five years and higher, the rate of stroke is $8.1 \%$; also, those with ejection fraction of less than $28 \%$ have relatively much higher risk of stroke.

In a follow-up study, diabetes individuals had nearly $23 \%$ higher risk of developing ischemic stroke. The incidence was about $20 \%$ higher among those with advancing age. Moreover, patients with higher levels of insulin resistance were more likely to have a first ischemic stroke. ${ }^{60}$ The metabolic syndrome (obesity, glucose dysmetabolism, hypertension, and dyslipidaemia) has been shown to confer a greater risk of first and recurrent stroke. ${ }^{61}$ It is unclear whether metabolic syndrome confers a greater risk of first stroke than what one would expect for its components. ${ }^{62}$ Finally, asymptomatic carotid stenosis with surge as a potential cause of ischemic stroke rises with age. This can be important to consider in those $>50$ and is found in nearly $60 \%$ of stroke patients. Current medical treatment has led to much better prognostic outcomes, with the result that the risk of stroke associated with asymptomatic carotid stenosis has fallen significantly during the past 20 years. ${ }^{63}$

Preventable life style risk factors: Smoking is associated with lesser blood vessel elasticity, high fibrinogen levels, augmented platelet aggregation, higher haematocrit, and high density lipoprotein cholesterol levels. ${ }^{64}$ Depending upon the dose-response relationship, for smokers the relative risk of stroke compared with statistics from earlier studies was near to twofold. ${ }^{65}$ and a dose-response association with higher stroke risk has been observed in heavy versus light smokers. Stroke risk decreases with smoking cessation for five years. Even passive cigarette smoking boosts progression of atherosclerosis and entails a greater risk of stroke. Further, smoking facilitates the action of oral contraceptives, enhancing the risk of stroke by several folds.$^{64}$

Increased physical activity is associated with lowering of fibrinogen, homocysteine, and platelet activity. It is also associated with elevation of high-density lipoproteins and increased plasminogen activator activity. Therefore, increased physical activity is associated with much lower risk of stroke, whereas sedentary behaviour is associated with higher stroke risk.

High stroke risk has been associated with all stages of hypertension and isolated systolic hypertension. ${ }^{20}$ In fact, the risk of stroke seems to have a continuous association with blood pressure down to levels as low as $115 / 75 \mathrm{mmHg} .{ }^{61}$ In light of this, the national guidelines redefined categories of hypertension so that normal systolic blood pressure is $<120 \mathrm{mmHg}$ and normal diastolic blood pressure is $<80$ mmHg. ${ }^{66}$ Most recently, it has been suggested that variability in blood pressure measurements (visit to visit, distinct measurements within a given visit) are associated with greater risk of stroke. ${ }^{67}$

\section{Stroke outcomes}

The overall death rates from stroke in industrialized countries among people over age 65 years is about $10 \%-12 \%$, and nearly $88 \%$ of the deaths ascribed to stroke are among people over 65 years. In recent decades, in most industrialized nations, a decline of about $7 \%$ has been documented.$^{68}$ with average annual declines of up to $7 \%$ since 1970 . Death rates from stroke have fallen dramatically in Japan and the United States. ${ }^{69}$ Nevertheless, stroke is still the fourth most important cause of death in the United States and the top cause of enduring disability worldwide. It is estimated that, in the United States, someone dies of stroke every four minutes. By contrast, with changing risk factors for stroke, death rates have increased over the past two decades in some eastern European countries such as the Czech Republic, Hungary, and Bulgaria. ${ }^{69}$

Effect of age on outcomes: The incidence of stroke has direct link with age, and in-hospital mortality and case fatality also increase with advancing age. People $\geq 80$ years old with stroke had a longer length of stay in contrast to younger patients $(24.7 \pm 27.6$ vs. $22.3 \pm 24.2$ days; $p=0.013$ ) [70]. Furthermore, case fatality rate for the same age group can be as high as $21 \%{ }^{71}$ Although age seems to influence activities of daily living recovery, it has not been found to have an outcome on neurological recovery. ${ }^{72}$ This fact may suggest that older patients have a poorer capability to recover, and therefore may benefit from rehabilitation with a focal point on activities of daily living. ${ }^{73}$

Effect of gender on outcomes: There are insufficient data identifying gender as a cause of mortality from stroke. Due to their longevity, the overall age-adjusted stroke mortality rates for men are more than for women, yet every year more women die of stroke than men. Women accounted for nearly $61 \%$ of all stroke deaths in the United States in 2015 and 2016. ${ }^{74}$ This is because women have more severe strokes than men. ${ }^{75}$ In the ongoing study, case fatality for men was $20.2 \%$ and for women it was $25.5 \%$; therefore, it is about 1.26 times higher among women. Furthermore, women who survive stroke appear to have fewer encouraging outcomes than men. Health care facility stays among women are comparatively longer. ${ }^{75}$ Women have comparatively less favourable prognoses and worse self-care at 3 to 6 months post stroke, even after adjustment for age, comorbidities, and other clinical features. ${ }^{76}$ It is unclear why these gender differences exist.${ }^{77}$

Effect of socioeconomic status on outcomes: The relationship between poverty and health inequality has been demonstrated in many different countries and at different levels of national healthcare coverage. ${ }^{77}$ What drives this relationship is unclear, because comparisons between published studies are difficult to make due to the heterogeneity of the studies, including the choice of which indicator of socioeconomic status (SES) to measure (income, education, occupation, class, and so forth). The fact remains that these proxy measures of SES have been shown to be inversely associated with stroke case fatality, poorer functional and motor recovery during rehabilitation, less health services after stroke, and increased recurrent stroke risk. $^{78}$

Stroke burden and mortality vary greatly geographically, but lowincome countries are the most affected. ${ }^{79}$ Some possible mechanisms by which SES variables are associated with disease outcomes are by creating differentials in the use of social support structures, healthcare. Non communicable diseases like stroke are the leading killers in low and middle income countries like Pakistan. ${ }^{80} \mathrm{~A}$ cross-sectional survey from a multi-ethnic transitional Pakistani community showed that almost a quarter of the respondents had suffered a cerebrovascular event (either a stroke or a TIA). ${ }^{81}$ Thus, there is a need to generate regionally specific data from these regions to formulate effective management strategies for stroke survivors.

There are studies done in developed countries exploring the functional and cognitive outcomes of stroke. ${ }^{82}$ Data from Pakistan 
are restricted to a few hospital-based studies that have reported mortality and acute complications..$^{83}$ but nothing is known of the post hospital outcomes of stroke survivors. There are reasons to suspect that outcomes from stroke in developing countries like Pakistan may be sufficiently different from the developed world to merit investigation. Stroke aetiology is different, intracranial disease being more common. ${ }^{83}$ intracranial haemorrhage (ICH) constitutes a higher proportion of strokes; patients are younger and ethnically distinct. A recent study has highlighted this regional difference in stroke outcomes and mortality reported in various stroke trials. ${ }^{84}$

In developing countries like Pakistan, stroke is the leading cause of death and disability. Incidence of stroke is documented more in urban areas than rural region of this country. ${ }^{85}$ The apparent cause is frequent travel automobiles, sedentary habits, and relative anxiety and apprehension. The urban to rural incidence ratio is $3: 2$. It is relatively more in affluent than poor working class of communities because of sedentary habits and easier lives compared with the working class. The incidence rate is 1:4. ${ }^{77}$ Incidence of stroke is more in cold climates like northern areas, the high altitudes mountainous belt extending from Pakistan, boarder regions of China, Afghanistan, and Iran (Figure 1).

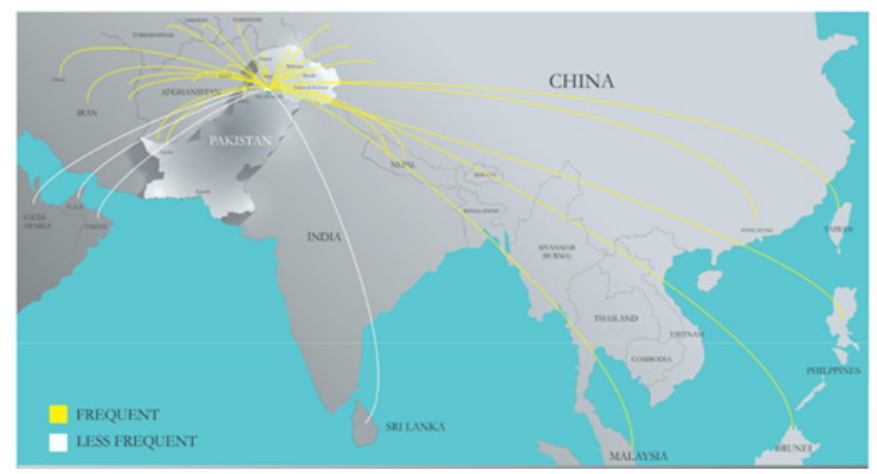

Figure I Map showing frequent and less frequent flow of patients of stroke in South Asia and neighboring countries seeking treatment from International Stroke Center in Pakistan.

A lack of attention to diagnosis of potential risks such as hypertension, diabetes mellitus, valvar heart diseases, including rheumatic heart diseases, is a dominant cause.$^{84}$ Incidence of recurrent stroke is more common in cured stroke patients who ignore the management of hypertension, diabetes mellitus, and mental stress and strain. ${ }^{85}$ In almost all cases, it is lack of understanding/ignorance on optimal control of preventable risk factors, secondary prophylaxis for patients with rheumatic heart disease.$^{85}$ and access to knowledge and resources. ${ }^{86}$

\section{The global burden of cerebrovascular accident}

In general, the trends in stroke incidence and mortality rates have decreased in recent decades in developed countries (the United States, the United Kingdom, and Canada). ${ }^{87}$ This tendency may reflect both an improvement in risk factor control, as well as an improvement in life expectancy owing to reduced hypertension, hyperlipidaemia, smoking reduction, and, in part, nutritional supplements. In addition, an improvement in acute stroke care may have led to an overall reduction in the percentage of stroke hospitalizations resulting in death in the United States. While there have been reports of reduction in stroke incidence and mortality in developed countries, the opposite has been observed in low-to-middle income countries. ${ }^{71}$ However, the overall early stroke case fatality in low-to-middle income countries is found to be $25 \%$ higher than that seen in high-income countries in the past decade. The reasons for these differences are unclear, however, in the low income case, patients are unlikely to have access to the same advancements in acute stroke care and secondary stroke prevention measures as seen in in the high-income countries in the recent decades. Although advancement in stroke prevention and management has led to many successes in the fight against cerebrovascular disease for the past two decades, numerous challenges still remain to address, as clinicians and investigators try to uncover the underlying causes behind the many disparities in stroke burden and outcome observed in epidemiologic studies to be able to design interventions to improve stroke mortality and disability for all.

\section{Materials and methods}

To determine the prevalence of risk factors in Pakistani stroke patients, we collected data from four hospitals concerned with treatment of patients with stroke (Al-Junaid Hospital, National Medical Center Nowshera KPK Pakistan, Yusra Teaching Hospital and Medipro Hospital Rawalpindi Pakistan) from August 01, 2016 till September 10, 2017. To ensure ethical soundness of the study, we received approval from the review boards at each institution, and we did not collect identifying patient data.

Patients were asked to describe in detail When, How, Where they got stroke and to speak a sentence of his native language, move his/ her affected arm and leg as directed by the clinician. For patients who were unable to speak, the description of their illness was given by the attendant(s). The data contained patient's clinical and biometric parameters (name, age, gender, habitat, occupation), details of his/ her level of brain vessels/ nerve damage, and presentation of risk factors for stroke such as, hypertension, diabetes mellitus, pregnancy, contraceptive use, obesity (overweight), smoking, heart diseases (ischemic heart diseases, rheumatic heart diseases, dysrhythmias, hyperlipidaemia).

We calculated descriptive statistics (totals and percentages) to estimate the percentages of the sample that had the following risk factors: pregnancy/prolonged contraceptive use, overweight associated with diabetes mellitus and hypertension, tobacco use and smoking, heart diseases (ischemic heart disease, dysrhythmias (arterial flutter/arterial fibrillation). To determine whether these incidences of risk factors differed between urban and rural populations in Pakistan, we calculated descriptive statistics (totals and percentages) for each of the relevant risk factors, stratified by urban/rural location.

Finally, to determine whether there is a difference between incidence of stroke in Pakistan and developed nations, we identified stroke incidence figures for Germany, France, Japan, the United Kingdom, the United States, Italy, and China. We calculated differences in the rate of stroke per 100,000 population between each country and Pakistan. Stroke incidence rates were sampled at various times depending on available literature, between 2006 and 2017.

\section{Results}

Table 1 presents the demographic characteristics of the sample. The sample was predominantly female $(64 \%)$, and the largest percentage of patients was between 55 and 65 years of age. Because Pakistan is not ethnically diverse, we present residence location and socioeconomic status to further characterize the sample. Most participants were from the non-mountainous regions of Pakistan and were at or below middle class. 
Table I Sample Demographics, $n=1,180$

\begin{tabular}{|c|c|c|}
\hline Variable & $\mathbf{N}$ & $\%$ \\
\hline \multicolumn{3}{|l|}{ Female Age, $n=760$} \\
\hline $14-22$ years & 76 & $10 \%$ \\
\hline 30 - 50 years & 114 & $15 \%$ \\
\hline $55-65$ years & 152 & $20 \%$ \\
\hline $66-80$ years & 190 & $25 \%$ \\
\hline $81-100$ years & 228 & $30 \%$ \\
\hline \multicolumn{3}{|l|}{ Male Age, $n=420$} \\
\hline $14-22$ years & 21 & $5 \%$ \\
\hline $30-50$ years & 42 & $10 \%$ \\
\hline $55-65$ years & 105 & $25 \%$ \\
\hline $66-80$ years & 126 & $30 \%$ \\
\hline $81-100$ years & 126 & $30 \%$ \\
\hline \multicolumn{3}{|l|}{ Residence Location, $\mathrm{n}=1 \mathrm{I} 80$} \\
\hline Higher than sea level & 283 & $24 \%$ \\
\hline Plain area & 897 & $76 \%$ \\
\hline \multicolumn{3}{|l|}{ Socio-economic Status, $\mathrm{n}=1 \mathrm{I} 80$} \\
\hline Below poverty to middle class & 732 & $62 \%$ \\
\hline Higher income & 448 & $38 \%$ \\
\hline
\end{tabular}

Incidence of stroke risk factors in pakistani stroke patients

For the first research question, "What are the percentages of incidence of risk factors in Pakistani stroke patients?" we calculated descriptive statistics for our sample of 1,180 Pakistani stroke patients. Results indicated that the most prevalent risk factor was pregnancy/prolonged contraceptive use, which was found in $65.4 \%$ of our sample. This was the only risk factor present in over half of the sample. Risk factors appearing in between $30 \%$ and $50 \%$ of the sample included overweight associated with diabetes mellitus and hypertension $(49.00 \%)$, smoking $(41.7 \%)$ and ischemic heart disease (34.5\%). Risk factors appearing in between $10 \%$ and $30 \%$ of the sample included obesity/overweight (23.8\%), hypertension (22.8\%), dysrhythmias/arterial flutter/arterial fibrillation (18.9\%), and diabetes mellitus (14.0\%). Finally, the lowest percentage had valvar/rheumatic heart disease (1.4\%). Table 2 summarizes these results.

Table 2 Percent of Preventable Risk Factors for Stroke Patients, $n=1,180$

\begin{tabular}{ll}
\hline Preventable Risk Factors & Percent \\
\hline Pregnancy/prolonged contraceptive use & $65.40 \%$ \\
Overweight associated with diabetes mellitus and hypertension & $49.00 \%$ \\
Smoking & $41.70 \%$ \\
Ischemic heart disease & $34.50 \%$ \\
Obesity/overweight & $23.80 \%$ \\
Hypertension & $22.80 \%$ \\
Dysrhythmias (atrial flutter, atrial fibrillation) & $18.90 \%$ \\
Diabetes mellitus & $14.00 \%$ \\
Valvar/Rheumatic Heart Disease & $1.40 \%$
\end{tabular}

Differences in stroke risk between urban and rural pakistani populations

The second research question asked, "Are there differences in the percentage patients with risk factors between urban and rural stroke patients?" To answer this research question, we calculated percentages for each risk factor, stratified by urban and rural location. Results indicated that the urban patients were more prone to all of the risk factors except valvar/rheumatic heart disease, where rural patients had a very slightly higher incidence. Table 3 for a summary of results. As Table 2 shows, the pattern of incidences was about the same for both groups, with the highest and lowest percentages closely reflecting the result for the overall sample. With respect to the most prevalent risk factor, pregnancy/prolonged contraceptive use, the incidence was higher by $24.6 \%$ in the urban population compared with the rural population. For the other risk factors, the differences were much smaller, ranging from $3.8 \%$ to $9.8 \%$.

Table 3 Stroke Patients (Urban and Rural) with Each Preventable Risk Factor

\begin{tabular}{llll}
\hline Preventable Risk Factors & Urban & Rural & Difference \\
\hline $\begin{array}{l}\text { Pregnancy/prolonged contraceptive use } \\
\text { Overweight associated with diabetes mellitus }\end{array}$ & $70.10 \%$ & $45.50 \%$ & $24.60 \%$ \\
and hypertension & $50.90 \%$ & $41.10 \%$ & $9.80 \%$ \\
Tobacco use as smoking & $42.40 \%$ & $38.60 \%$ & $3.80 \%$ \\
Ischemic heart diseases & $36.10 \%$ & $27.60 \%$ & $8.50 \%$ \\
Obesity /overweight & 25.2 & $17.90 \%$ & $7.30 \%$ \\
Hypertension & $23.10 \%$ & $18.10 \%$ & $5.00 \%$ \\
Dysrhythmias (atrial flutter, atrial fibrillation) & $20.60 \%$ & $11.40 \%$ & $9.20 \%$ \\
Diabetes mellitus & $14.80 \%$ & $10.40 \%$ & $4.40 \%$ \\
Valvar/rheumatic heart disease & $1.40 \%$ & $1.60 \%$ & $-0.20 \%$
\end{tabular}

Comparing incidence of stroke between pakistan and developed countries

To answer the third research question, "Is there a difference between Pakistani incidence of stroke and developed nations?" we compared rates per 100,000 population in Pakistan and seven countries. The rate of stroke per 100,000 in Pakistan is 250. The only country we examined with a higher rate of stroke was Germany, with an incidence of 350/100,000. The remaining countries had lower stroke rates, with the exception of China, were the stroke rate was about the same as that in Pakistan (247/100,000 population). Table 4 summarizes these results.

Table 4 Comparison of Incidence of Stroke in Pakistan and Developed Countries (Rate//00,000)

\begin{tabular}{lll}
\hline Country/Region & Rate & Difference \\
\hline Pakistan & 250 & \\
Germany & 350 & -100 \\
Italy & 223 & 27 \\
UK & 161 & 89 \\
France & 114 & 136 \\
US & 200 & 50 \\
Japan & 130 & 120 \\
China & 247 & 3
\end{tabular}

\section{Discussion and conclusions}

Our results yield some novel information about stroke risk factors in Pakistan. Most interestingly, pregnancy and prolonged contraceptive use were the most important risk factors in our sample. This differs from existing literature from other countries like the United States, where hypertension..$^{51-53}$ is the most important risk factor. In our sample hypertension affected only $22.8 \%$ of Pakistani stroke patients. This indicates that best practices and intervention strategies designed to target the most common risk factors for stroke may not be applicable or of great utility in Pakistan if they are based on data regarding risk factors from other geographical locations. In particular, heart health and stroke prevention among pregnant and sexually active women using contraception deserves an increased focus. Owing to the scarcity of data on stroke risk factors and epidemiology in Pakistan, further research is warranted to confirm our findings and understand more about the reasons for the high incidence of pregnancy/prolonged contraceptive use as a risk factor for stroke. 
Second, our study indicated that, in most cases, risk factors have similar prevalence rates among urban and rural populations. However, pregnancy/prolonged contraceptive use is much more prevalent (by 24\%) among urban Pakistani stroke patients than rural Pakistani stroke patients. There could be several explanations for this finding. First, it could reflect lower rates of contraceptive use among rural Pakistani populations, where contraception is less available and may be looked upon as immoral. Second, it could reflect differing lifestyles among pregnant and sexually active women using contraception between urban and rural Pakistani populations. Further research will be required to clarify this finding and control for confounding variables. It is recommended, additionally, that further research be carried out to ensure that contraceptives used by Pakistani women are safe for prolonged use, and to ensure that urban Pakistani women are well educated on the safe use of contraception.

In conclusion, our international comparative data are interesting in that they reveal a high incidence of stroke among Pakistani patients compared with most developed countries. This suggests an increased need to emphasize research and intervention for stroke, in order to reduce the disease burden from stroke in Pakistan. This study is subject to certain limitations, which readers should take into consideration when interpreting our results. First, our data lack specificity regarding demographic data, lifestyle factors, and other information that could shed light on the incidence of risk factors, particularly among women. Second, we present only descriptive data, so we do not make claims regarding the statistical significance of our findings. Further research will be needed to establish significance. Finally, our international comparison data are drawn from a small sample of studies across over a decade of time. More recent, robust, and directly comparable data will be needed to confirm and strengthen any conclusions made on the basis of these international differences.

\section{Acknowledgements}

None.

\section{Conflicts of interest}

None.

\section{References}

1. Batty GD, Russ TC, Stamatakis E, Kivimäki M. Psychological distress in relation to cite specific cancer mortality: pooling of unpublished data from 16 prospective cohort studies. BMJ. 2017:356:j108.

2. Roy A, Mehra S, Kelly CP, Tariq S, et al. The association between socioeconomic status and the symptoms at diagnosis of celiac disease: a retrospective cohort study. Therap Adv Gastroenterol. 2016:9(4):495-502.

3. Wu X, Zhu B, Fu L, et al. Prevalence, Incidence, and Mortality of Stroke in the Chinese Island Populations: A Systematic Review. PLoS One. 2013:8(11):e78629.

4. Feigin VL, Krishnamurthi RV, Parmar P, Norrving B, Mensah GA, et al (2015) Update On The Global Burden Of Ischaemic And Haemorrhagic Stroke In 1990-2013: The Gbd 2013 Study. Neuroepidemiology 45(3): 161-176.

5. Salameh EMP, Rachidi S, Hosseini H. The epidemiology of stroke in the Middle East. European Stroke Journal. 2016:1(3):180-198.

6. Béjot Y, Bailly H, Durier J, et al. Epidemiology of stroke in Europe and trends for the $21^{\text {st }}$ century. Presse Med. 2016:45(12 Pt 2):e391-e398.

7. Gusev EI, Skvortsova VI, Stakhovskaia LV. Epidemiology of stroke in Russia. Zh Nevrol Psikhiatr Im S S Korsakova Suppl. 2003:8:4-9.
8. Stroke Association. The nation Stroke statistics January 2017.Together we can conquer stroke. Zh Nevrol Psikhiatr Im S SKorsakova. 2003:(Suppl 8):4-9.

9. Marcin J, Ellis ME, Mary Ellen Ellis. Cerebrovascular Accident. 2017.

10. Wong ND. Epidemiological studies of CHD and the evolution of preventive cardiology. Nat Rev Cardiol. 2014:11(5):276-289.

11. Wang W, Jiang B, Sun H, et al. Prevalence, Incidence and Mortality of Stroke in China: Results from a Nationwide Population-Based Survey of 480, 687 Adults. Circulation. 2017:135(8):759-771.

12. Shafqat $\mathrm{S}$. Clinical practice guidelines for the management of ischemic stroke in Pakistan. J Pak Med Assoc. 2003:53(12):600-603.

13. Adams HP Jr, Kappelle LJ, Biller J, et al. Ischemic stroke in young adults. Experience in 329 patients enrolled in the Iowa registry of stroke in young adults. Arch Neurol. 1995:52(5):491-495.

14. Banerjee TK, Mukherjee CS, Sarkhel A. Stroke in the urban population of Calcutta - an epidemiological study. Neuroepidemiology. 2001:20:201-207.

15. Ford AL, Williams JA, Spencer M, et al. Reducing door-to-needle times using Toyota's lean manufacturing principles and value stream analysis. Stroke. 2012:43:3395-3398.

16. Basharat RA, Yousaf M, Iqbal J. Frequency of known risk factors for stroke in poor patients admitted to Lahore general hospital in 2000. Pak J Med Sci. 2002:18:280-283.

17. Ahmad A, Usman F, Hassan A. Risk factors and pattern of stroke in Islamabad, Pakistan. Rawal Med J. 2009:34(1):47-50.

18. http://pakneurology.net/pages/StrokeSociety.asp

19. ChandP, IbrahimS, Matloob Muhammad A, et al. Acute childhood ischemic stroke: a Pakistani tertiary care hospital experience, Pakistan $J$ Neurol Sci. 2016:11(1):1-5.

20. MemonTF, Lakhair MA, Shaikha, et al. Socio-demographic risk factors for hemorrhagic and ischemic stroke: a study in tertiary care hospital of Hyderabad. Pak J Neurol Sci. 2016:11(1):1-7.

21. Saleheen D, Bukhari S, Haider SR, et al. Association of phosphodiesterase $4 \mathrm{~d}$ gene with ischemic stroke in a Pakistani population. Stroke. 2005:36(10):2275-2277.

22. Khawaja I, Shakoor Z. Hypertension is a major risk factor for stroke in men and women of all ages. J Pak Inst Med Sci. 1993:4(1,2):191-194.

23. Khan MN, Nadeem M, Ayyub M, et al. Lupus anticoagulant: a cause of stroke in young adults. Pak J Pathol. 1999:10(2):4-6.

24. Ansari AK, Akhund IA, Shaikh AQ. Stroke in elderly: identification of risk factors. J Ayub Med Coll Abbottabad. 2001:13(3):11-13.

25. Basharat RA, Yousuf M, Iqbal J, et al. Frequency of known risk factors for stroke in poor patients admitted to Lahore General Hospital in 2000. PakJ Med Sci. 2002:18(4):280-283.

26. Syed NA, Khealani BA, Ali S, et al. Ischemic stroke subtypes in Pakistan: the Aga Khan university stroke data bank. J Pak Med Assoc. 2003:53(12):584-588.

27. Niaz A, Nayyar S. Cerebrovascular stroke at high altitude. J Coll Physicians Surg Pak. 2003:13(8):446-448.

28. Qureshi MA, Jamshaid TD, Siddiqui AM. Stroke-a study of clinical patterns and risk factors. Ann King Edward Med Coll. 2003:9:98-100.

29. Alam I, Haider I, Wahab F, et al. Risk factors stratification in 100 patients of acute stroke. J Postgrad Med Inst. 2004:18(4):583-591.

30. Sherin A, Shabbier G, Rehman S, et al. Hypertension in acute ischemic and hemorrhagic stroke. J Postgrad Med Inst. 2005:19(2):220-225. 
31. Khan J, Attique ur R, Ali Shah A, et al. Frequency of hypertension in stroke patients presenting at Ayub Teaching Hospital. J Ayub Med Coll Abbottabad. 2006:18(1):59-61.

32. Khan H, Afridi AK, Ashraf S. A hospital based study on stratification of risk factors of stroke in Peshawar. PakJ Med Sci. 2006:22(3):304-307.

33. Khan J, ur Rehman A. Comparison of clinical diagnosis with computed tomography in ascertaining type of stroke. J Ayub Med Coll Abbottabad. 2005:17(3):65-67.

34. Khan SN, Vohra EA. Risk factors for stroke: a hospital based study. Pak J Med Sci. 2007:23(1):17-22.

35. Vohra EA, Ahmed WU, Ali M. Aetiology and prognostic factors of patients admitted for stroke. J Pak Med Assoc. 2000:1-7.

36. Basir F, Ali S, Aziz H. Stroke recovery and outcome in diabetes. J Coll Physicians Surg Pak. 2001:11(12):736-738.

37. Naseem A, Mahmood, Hussain T, et al. Clinical spectrum of stroke in our adult population. Pak Armed Forces Med J. 2003:53(1):59-67.

38. Khan A, Sherin A, AhmadH, et al. Acute complications of stroke. $J$ Postgrad Med Inst. 2004:18(2):220-224.

39. Hassan A, Khealani BA, Shafqat S, et al. Stroke-associated pneumonia: microbiological data and outcome. Singapore Med J. 2006:47(3):204-207.

40. Hasan Y, Ilyas MS, Sheikh AM, et al. Transcranial doppler sonography in acute ischaemic stroke. J Coll Physicians Surg Pak. 2002:12(6):331-334.

41. Shams-ur-Rehman, Khan MA. Clinical versus CT scan diagnosis in stroke-a comparative study of 50 cases. J Ayub Med Coll Abbottabad. 2002:14(1):2-5

42. Mahsud ZS, Gul H. Risk factors and comparison of CT versus clinical findings in stroke. PakJ Med Sci. 2003:11: 53-58.

43. Khan JA, Shah MA. Young stroke - clinical aspects. J Coll Physicians Surg Pak. 2000:10(12):461-466.

44. Razzaq AA, Khan BA, Baig SM. Ischemic stroke in young adults of South Asia. J Pak Med Assoc. 2002:52(9):417-422.

45. Siddiqui TS, Rehman A, Ahmed B. Etiology of strokes and hemiplegia in children presenting at Ayub Teaching Hospital, J Ayub Med Coll Abbottabad. 2006:18(2):60-63.

46. Khealani BA, Javed ZF, Syed NA, et al. Cost of acute stroke care at a tertiary care hospital in Karachi, Pakistan. J Pak Med Assoc. 2003:53(11):552-555

47. Khawar S, Rafiq S. Circadian fluctuation in timing of onset of acute ischemic stroke. Biomedica. 1996:12:37-38.

48. Basharat RA, Ellahi A, Tariq M, et al. One month audit of stroke at PIMS. Pak J Neurol. 1999:5(1):12-16.

49. Ahmed R, Zuberi BF, Afsar S. Stroke scale score and early prediction of outcome after stroke. J Coll Physicians Surg Pak. 2004:14(5):267-269.

50. Paul CL, Levi CR, D'Este CA, et al. Thrombolysis Implementation in Stroke (TIPS) Study Group. Thrombolysis Implementation in Stroke (TIPS): evaluating the effectiveness of a strategy to increase the adoption of best evidence practice-protocol for a cluster randomised controlled trial in acute stroke care. Implement Sci. 2014:9:38.

51. Butcher K, Shuaib A, Saver J, et al. Thrombolysis in the developing world: is there a role for streptokinase? Int J Stroke. 2013:8:560-565.

52. Buchan AM, Barber PA, Newcommon N, et al. Effectiveness of t-PA in acute ischemic stroke: outcome relates to appropriateness. Neurology. 2000:54(3):679-684.

53. Xu ZP, Li HH, Li YH, et al. Feasibility and outcomes of intravenous thrombolysis 3-4.5 hours after stroke in Chinese patients. J ClinNeurosci. 2014:21:822-826.
54. Ko Y, Lee S, Chung JW, et al. MRI-based algorithm for acute ischemic stroke subtype classification. J Stroke. 2014:16(3):161-172.

55. Kennedy J, Hill MD, Ryckborst KJ, et al. FASTER Investigators. Fast assessment of stroke and transient ischaemic attack to prevent early recurrence (FASTER): a randomized controlled pilot trial. Lancet Neurol. 2007:6(11):961-969.

56. Johnston SC, Gress DR, Browner WS, et al. Short-term prognosis after emergency department diagnosis of TIA. JAMA. 2000:284(22):2901-2906.

57. FeiginVL. Stroke epidemiology in the developing world. Lancet. 2005:365(9478):2160-2161.

58. MurrayCJ, LopezAD. Mortality by cause for eight regions of the world Global Burden of Disease Study. Lancet. 1997:349:1269-1276.

59. Mubashirah Hashmi, Maria Khan, Mohammad Wasay. Growing burden of stroke in Pakistan: a review of progress and limitations. International Journal of Stroke. 2013:8(7):575-581.

60. Kim P, Warren S, Madill H, et al. Quality of life of stroke survivors Qual Life Res. 1999:8(4):293-301.

61. Ostwald SK, Bernal MP, Cron SG, et al. Stress experienced by stroke survivors and spousal caregivers during the first year after discharge from inpatient rehabilitation. Top Stroke Rehabil. 2009:16(2):93-104.

\section{PAKISTAN GP}

63. Rangel ESS, Belasco AGS, Diccini S. Quality of life of patients with stroke rehabilitation. ActaPaulista de Enfermagem. 2013:26(2):205-212.

64. Akosile CO, Adegoke B, Ezeife CA, et al. Quality of life and sexdifferences in a south-eastern Nigerian stroke sample. Afr J Neurol Sci. 2013:32(1):19-25

65. Kamal AK, Itrat A, Murtaza M, et al. The burden of stroke and transient ischemic attack in Pakistan: a community-based prevalence study. BMC Neurol. 2009:9(1):58.

66. Kamal AK, Majeed F, Pasha O, et al. Clinical, lifestyle, socioeconomic determinants and rate of asymptomatic intracranial atherosclerosis in stroke free Pakistanis. BMC Neurol. 2014:14(1):155.

67. Chuang Ll, Wu CY, Lin KC, et al. Relative and absolute reliability of a vertical numerical pain rating scale supplemented with a faces pain scale after stroke. Phys Ther. 2014:94(1):129-138

68. Cadilhac DA, Dewey HM, Vos T, et al. Research The health loss from ischemic stroke and intracerebral hemorrhage: evidence from the North East Melbourne Stroke Incidence Study (NEMESIS) Health Qual Life Outcomes. 2010:8:49.

69. Akpalu J, Akpalu A, Ofei F. The metabolic syndrome among patients with cardiovascular disease in Accra, Ghana. Ghana Med J. 2011:45(4):161-166

70. Brown $\mathrm{C}$, Hasson $\mathrm{H}$, Thyselius $\mathrm{V}$ et al. Post stroke depression and functional independence: a conundrum. Acta Neurol Scand. 2012:126(1) 45-51.

71. Khan M, Ahmed B, Ahmed $\mathrm{M}$ et al. Functional, cognitive and psychological outcomes, and recurrent vascular events in Pakistani stroke survivors: a cross sectional study. BMC Res Notes. 2012:5(1):89.

72. Mitchell PH, Powell L, Blumenthal J et al. A short social support measure for patients recovering from myocardial infarction: the ENRICHD Social Support Inventory. J Cardiopulm Rehabil Prev. 2003:23(6):398-403.

73. Williams LS, Weinberger M, Harris LE et al. Development of a strokespecific quality of life scale. Stroke.1999:30(7):1362-1369.

74. Godwin KM, Ostwald SK, Cron S et al. Long-term health related quality of life of survivors of stroke and their spousal caregivers. J Neurosci Nurs. 2013:45(3):147. 
75. Cohen S, Kamarck T, Mermelstein R A global measure of perceived stress. J Health Soc Behav. 1983:24(4):385-396.

76. Polit DF, Beck CT The content validity index: are you sure you know what's being reported? Critique and recommendations. Res Nurs Health. 2006:29(5):489-497.

77. Sangoseni O, Hellman M, Hill C Development and validation of a questionnaire to assess the effect of online learning on behaviors, attitudes, and clinical practices of physical therapists in the united states regarding evidence-based clinical practice. Int J Allied Health SciPract. 2013:11(2):1-13.

78. Nunnally JC, Bernstein IH Psychometric Theory. New York: McGrawHill: 1978. 33. Santos JRA. Cronbach`s alpha: a tool for assessing the reliability of scales. $J$ Ext. 1993:37(2):1-5.

79. Kamel A, Ghani AA, Zaiton MA et al. Health related quality of life in stroke survivors measured by the Stroke Impact Scale. Egypt J Neurol Psychiatry Neurosurg. 2010:47267-47274.

80. David W Hosmer J, Stanley Lemeshowand Rodney X Sturdivant Applied Logistic Regression. (3rd edn), Wiley Online, USA. 2013
81. Agunloye AM, Owolabi MO Exploring carotid sonographic parameters associated with stroke risk among hypertensive stroke patients compared to hypertensive controls. J Ultrasound Med. 2014:33(6):975-983.

82. Ali TS, Krantz G, Gul R et al. Gender roles and their influence on life prospects for women in urban Karachi, Pakistan: a qualitative study. Glob Health Action. 2011:4:7448.

83. Bogdan R, Biklen SK Qualitative research in education: an introduction to theory and methods. (5 ${ }^{\text {th }}$ edn), Allyn\& bacon, Boston, USA. 2006

84. Michael Lewis-Beck AEB, Tim Futing Liao The SAGE Encyclopedia of Social Science Research Methods. SAGE Publications. 2004

85. Nishtar S, Bhutta ZA, Jafar TH et al. Health reform in Pakistan: a call to action. Lancet. 2013:381(9885):2291-2297.

86. Walnut Creek Left Coast Press Inc. 2009

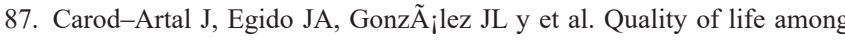
stroke survivors evaluated 1 year after stroke experience of a stroke unit. Stroke 31(12):2995-3000. 